\title{
Optical Fiber Waste Used as Reinforcement for Concrete with Recycled Marble Aggregate
}

\author{
Maria Teresa Barbosa ${ }^{1}$, White José dos Santos ${ }^{2}$, Zélia Ludwig ${ }^{1}$, Nelson Luis Dias de Souza ${ }^{3}$, Rodrigo Stephani ${ }^{1}$ \\ $\&$ Luiz Fernando Cappa de Oliveira ${ }^{1}$ \\ ${ }^{1}$ Federal University of Juiz de Fora - UFJF, Juiz de Fora, Minas Gerais, Brazil \\ ${ }^{2}$ Federal University of Minas Gerais - UFMG, Belo Horizonte, Minas Gerais, Brazil \\ ${ }^{3}$ Federal University of Tocantins - UFT, Palmas, Tocantins, Brazil \\ Correspondence: Maria Teresa Barbosa, Civil Construction Department, Engineering Faculty, Federal University \\ of Juiz de Fora, José Lourenço Kelmer St., University campus, São Pedro, Juiz de Fora, Minas Gerais, Brazil. \\ E-mail: teresa.barbosa@engenharia.ufjf.br
}

Received: December 13, 2020 Accepted: January 17, $2021 \quad$ Online Published: January 21, 2021

doi:10.5539/jms.v11n1p49 URL: https://doi.org/10.5539/jms.v11n1p49

\begin{abstract}
Sustainable development in the 21 st century depends on the reuse of materials and products, as well as on economic and environmental incentives for recycling. Several studies have sought to improve the quality of concrete, as well as its durability and strength, by adding fibers (metallic, polypropylene, carbon, vegetables) or by replacing the aggregate. The use of optical fiber waste in concrete is still incipient and few studies address the use of marble aggregate to be used in concrete. This research assesses the behavior of the mixture composed of: Portland cement + fine aggregate (sand from crushed marble waste) + coarse aggregate (gneiss) + optical fiber waste and water. The compressive strength, the tensile strength and the modulus of elasticity of concrete and the durability of optical fiber waste in alkaline composite were tested through microstructural evaluation. The results present an increase of about $20 \%$ in the mechanical properties and a reduction in the rigidity of the mixture, making the material more ductile. The superficial protection of the fibers made them more resistant to the alkaline attack of the cement. The knowledge acquired would allow the creation of sustainable concrete reinforced with optical fiber in a much more efficient way.
\end{abstract}

Keywords: concrete, waste, physicochemical analysis, sustainable development, glass fiber

\section{Introduction}

Currently, most industrial processes are sources of waste, causing major environmental degradation and compromising sustainable development (Cox et al., 2014; Almada et al., 2020). The current challenge concerns the rational use of waste arising from that system (Aliabdo, Elmoaty \& Auda, 2014; Ashish, 2018, Almada et. al., 2020). In such context, building industry, due to its large volume of resources consumed - either renewable or not - is one of the main technological sectors recommended for carrying out this absorption of solid waste (Munir, Kazmi \& Wu, 2017; Vardhan et al., 2015). The technical and scientific areas have experienced a boom with regard to studies that seek to find alternatives regarding the total replacement of the natural fine aggregate in order to face the growing shortage of supply and the resulting increase in its price, as well as the reuse of other waste from different sectors (Kou \& Agrela, 2011; Medina, Rojas \& Frias, 2013; Arel, 2016; Preira-Mercado et al., 2016).

In such context, studies developed in the early 2000's have evidenced the reuse of crushed marble waste as a fine aggregate for the manufacture of concrete and mortar (Barbosa, Santos \& Coura, 2018; Ashih, 2018). The consumption of ornamental marble stones (metamorphic rocks composed of calcite and dolomite) by the building industry raises a concern about the environmental impacts caused by the waste generated in the extraction and processing steps. It is estimated that $20-30 \%$ of the raw material is turned into waste (Buyuksagis, Uygunoglu \& Tatar, 2017). The largest amount of waste was obtained in the phases of extraction and primary processing (cutting the plates) and secondary processing (cutting the final pieces for ornamentation), and such waste can be used as aggregates (Ashish, 2019).

Most studies in the literature address the waste resulting from marbles when evaluating the use of marble 
aggregates as a substitute for fine aggregate, having been observed that there was a lower water demand in mortars containing up to $50 \%$ of those wastes. This can be explained by the marble powder thixotropy, which caused the mortar to flow with less energy when compared to the reference mixture. The increase in the incorporation content tends to increase the demand for water, reducing workability (Ashish, 2018). It was observed that the use of marble powder in the proportion of 10 to $15 \%$ in concrete increases the tensile and compressive strength by about 15 to $20 \%$, due to the reduction of the water/cement ratio (Singh, Srivastava, \& Bhunia, 2018). Moreover, lower w/c ratios promote lower porosity, which can be achieved with the use of plasticizer or superplasticizer admixtures (Sardinha, Brito \& Rodrigues, 2016). This is corroborated by the observation of the microstructure, which shows that the concretes with marble waste in the mixtures were denser, with a lower formation of crystals (calcium hydroxide and ettringite), reduced ITZ thickness and lower presence of large pores (Alyamaç \& Ince, 2009).

Other studies have sought to improve the quality of concrete, as well its durability and strength, by adding fibers such as metallic fibers (Yap et al., 2015a; Yap et al., 2015b), polypropylene (Lanzoni, Nobili \& Tarantino, 2012), carbon (Viana et al., 2020) and vegetables (coconut, sisal, among others). The fibers contribute to a greater toughness to tensile strength and to a reduction of the porosity and of the shrinkage cracks of concrete. Glass recycling is an environmental issue due to its high volume, the excessive cost of recycling it and its insolubility in the environment (Sales et al., 2017). There are many studies on the use of glass waste, such as: in cement mortars applied as pozzolan (Chen et al., 2002) and aggregate applied in concrete (Shayan \& Xu, 2006). In most research related to the addition of glass to concrete, the glass contains fine particles with a diameter of about 150 $\mu \mathrm{m}$ (different percentages of glass that increase in use as a replacement powder of cement and aggregates) (Ling, Poon \& Kou, 2012). The results of the application of glass powders in different percentages (lower than 20\%) indicated a slight increase in the compressive strength (Lee et al., 2011) and the tensile strength of the concrete. Research (Sales et al., 2017; Alvarenga et al., 2019) on the incorporation of glass waste as a fine aggregate in mortar or as a substitute for cement concluded that the presence of glass tends to reduce the heat conduction in these composites, improving thermal insulation properties.

The use of optical fiber waste in concrete is still incipient (Ge et al., 2015). The addition of that waste (Barbosa et al., 2013) results in a product with some qualities, specifically technical (quality proven by mechanical tests), environmental (high consumption of fiber residues from optical fiber waste) and economic (due to the possibility of reducing the size of the concrete pieces as opposed to the increase in tensile strength, consequently reducing the cost of the material). Also, from their implementation up to the end of their lifespan, optical fibers generate waste, as they are extremely thin and fragile. The handling of such fibers is delicate and, once broken, their waste cannot be fully reused for the same purpose, which promotes studies to reuse them in other industrial sectors. Besides that, the fiberglass is damaged by the degradation that can occur due to the alkalinity of Portland cement (Reis et al., 2009).

Therefore, this study aimed to analyze the durability of optical fiber waste (composed of dielectric, crystalline and homogeneous materials forming concentric capillaries) in an alkaline environment. Analyses of the mechanical properties of concrete were carried out, in which the incorporation of recycled aggregates and optical fiber waste and the behavior of the microstructure of glass fibers were evaluated after 5 years of exposure to alkaline compounds in concrete.

\section{Materials and Methods}

\subsection{Characterization of Materials}

It was used the high initial strength Portland cement (CPV-ARI-95\% clinker) (NBR 5733, 1991). Table 1 presents the general characterization of the cement. A coarse aggregate of gneiss was used, with the characteristics expressed in Table 2.

Table 1. Physical characterization of Portland Cement Type V

\begin{tabular}{llllll}
\hline Compounds & Content (\%) & Physical properties & \multicolumn{2}{c}{ Compressive strength (MPa) } \\
\hline $\mathrm{SiO}_{2}$ & 19.46 & Initial setting (min.) & 137 & days & $\mathrm{f}_{\mathrm{c}}$ \\
$\mathrm{Al}_{2} \mathrm{O}_{3}$ & 5.09 & End setting (min.) & 195 & 1 & 28.7 \\
$\mathrm{Fe}_{2} \mathrm{O}_{3}$ & 2.97 & (\%) Fineness \#325 & 1.7 & 3 & 42.6 \\
$\mathrm{CaO}$ & 64.61 & Volumetric expansion(mm) & 0.0 & 7 & 47.5 \\
$\mathrm{MgO}$ & 0.70 & Specific surface $\left(\mathrm{cm}^{2} / \mathrm{g}\right)$ & 4733 & 28 & 56.4 \\
$\mathrm{~K}_{2} \mathrm{O}$ & 0.80 & Loss on ignition $\left(1000^{\circ} \mathrm{C}\right)$ & 2.64 & & \\
$\mathrm{CO}_{2}$ & 2.05 & Insoluble waste $(\%)$ & 0.38 & & \\
$\mathrm{SO}_{3}$ & 2.99 & & & & \\
\hline
\end{tabular}


Table 2. Characterization of coarse aggregate

\begin{tabular}{ll}
\hline SIEVE - Opening $(\mathrm{mm})$ & Accumulated Total $(\%)$ \\
\hline 25.0 & 0.00 \\
19.0 & 16.53 \\
12.5 & 60.73 \\
9.5 & 90.93 \\
6.3 & 90.93 \\
4.8 & 90.93 \\
2.4 & 90.93 \\
1.2 & 90.93 \\
0.6 & 90.93 \\
0.3 & 90.93 \\
0.15 & 90.93 \\
$<0.15$ & 100.00 \\
Maximum characteristic size (mm) & 25.00 \\
Fineness Modulus & 6.53 \\
Specific mass $\left(\mathrm{kg} / \mathrm{d}^{3}\right)$ & 2.70 \\
Specific mass $\left(\mathrm{kg} / \mathrm{dm}^{3}\right)$ & 1.36 \\
Friable Material Content & Free \\
Powdered Material Content $(\%)$ & 5.36 \\
\hline
\end{tabular}

It has also been produced the artificial fine aggregate, from the marble waste crushing (WA). The chemical composition (Table 3) of the marble waste was determined by X-ray fluorescence (XRF), method XRF79C: fusion with lithium tetraborate, with $0.01 \%$ detection limit and using the CLA70C method for the determination of volumetric iron (II) - $\mathrm{FeO}$ (silicate) oxide. Loss on ignition was determined by calcination of the sample at $405^{\circ} \mathrm{C}$ and $/$ or $1000^{\circ} \mathrm{C}$, using the method PHY01E: LOI (Loss on ignition). The XRD (Table 4) was performed in a Bruker D2 Phaser with CuKa (1.54184 A) radiation; $30 \mathrm{kV}$ and $10 \mathrm{~mA}$; a step size of $0.018^{\circ}$ and step time of $1 \mathrm{~s}$; a 2 tetha range of $8-70^{\circ}$. The Rietveld refinement was carried out using the software X'Pert HighScore Plus 3.0 and the Crystallography Open Database (COD 2020). The samples were passed through a \#325 (45 microns) mesh sieve. Zincite (analytical grade, purity $>99 \%$ ) was used as an internal standard (20 wt $\%$, homogenized in an agate mortar for 10 minutes).

Table 3. Physical characteristics of the waste sand (WA)

\begin{tabular}{ll}
\hline Sand & Waste aggregate (WA) \\
\hline Maximum characteristic size $(\mathrm{mm})$ & $4.80 \mathrm{~mm}$ \\
Fineness Modulus & 2.75 \\
Specific mass $\left(\mathrm{kg} / \mathrm{dm}^{3}\right)$ & 2.91 \\
Specific mass $\left(\mathrm{kg} / \mathrm{dm}^{3}\right)$ & 1.74 \\
Powdered Material Content (\%) & $5.00 \%$ \\
Organic Impurity & $<300$ p.p.m. \\
Water Absorption (\%) & $1.27 \%$ \\
Abrasion "Los Angeles" (\%) & 63.10 \\
\hline
\end{tabular}

The reinforcement of the concrete was made with optical fiber waste. The size of the test specimen and the percentage of fiber significantly influence the indirect tensile strength, that is, for the same test specimen dimension, increasing the percentage of fiber will increase the strength (Barbosa et al., 2013). To assist in the morphological analyses of the fibers, a digital microscope with up to $1600 \mathrm{x}$ magnification was used.

\subsection{Characterization of Concrete}

The amount of fiber waste in the concrete was $1.4 \%$ in relation to the volume of concrete. The ratio of the concrete mixtures was 1: 1.83: 2.83 (cement: fine aggregate: coarse aggregate), whereas the water/cement ratios were 0.50 (for slump test $=140 \mathrm{~mm}$ ) and 0.46 (for slump test $=100 \mathrm{~mm}$ ). The experimental program consisted of analyzing the chemical and mechanical properties, namely: Raman spectra of the materials (cement, marble waste and concrete), compressive strength, tensile strength, flexural strength and modulus of elasticity.

A detailed investigation concerning the benefits of employing crushed marble waste as a fine aggregate in 
concrete properties promoted the use of Raman molecular spectroscopy to analyze the properties of the composite (Raman measurements were conducted with a Bruker RFS 100 spectrometer excited with a Nd p 3/YAG laser operating at $1.064 \mathrm{~nm}$, equipped with an InGaAs detector, cooled with liquid nitrogen), which allows the analysis of the microstructure (Oxford EDS INCA X-act detector - Instruments) and the verification of potential materials.

The compressive and tensile strengths of samples cured for 3, 7 and 28 days were determined using a Universal Testing Machine running at a loading of $0.3 \mathrm{MPa} / \mathrm{s}$ to $0.8 \mathrm{MPa} / \mathrm{s}$. Cylindrical specimens $(\mathbf{d}=10.0 \mathrm{~mm} ; \mathbf{h}=20.0$ $\mathrm{mm}$ ) were used for each formulation tested and the average data reported. The flexural strength of samples cured for 28 days was determined using a Universal Testing Machine running at a loading of $0.9 \mathrm{MPa} / \mathrm{min}$ to 1.1 $\mathrm{MPa} / \mathrm{min}$. Prismatic specimens $(150 \mathrm{~mm} \times 150 \mathrm{~mm}$ x $600 \mathrm{~mm}$ and span free $=450 \mathrm{~mm})$ were used for each formulation tested. To determine the modulus of elasticity, cylindrical specimens $(\mathrm{d}=15.0 \mathrm{~mm} ; \mathrm{h}=30.0 \mathrm{~mm})$, were used, which have been cured for 28 days, using a Universal Testing Machine running at a loading of 0.25 $\mathrm{MPa} / \mathrm{s}$.

\subsection{Analysis of Microstructure of Optical Fiber Waste in Concretes After 5 Years}

The concrete with optical fiber waste and a w/c ratio of 0.5 was maintained in laboratory conditions (relative humidity of $80 \pm 10 \%$ and temperature of $25 \pm 5^{\circ} \mathrm{C}$ ) for 5 years. The city presents the variations in temperature, sunlight, rainfall and relative humidity expressed in Figure 1. After this period, SEM microstructure analyzes were carried out to observe the fiber immersed in alkaline material such as Portland cement concrete. SEM images of secondary electrons were made in the VEGA3 Tescan microscope, with thermionic emission with tungsten filament, in high vacuum, with a voltage of $20 \mathrm{kV}$. Microscope images were taken from the inner surface of the cylinder specimen $(10 \times 20 \mathrm{~cm}$ - diameter $\mathrm{x}$ height $)$ for mixture with fiber using a digital microscope with up to $1600 \mathrm{x}$ magnification.
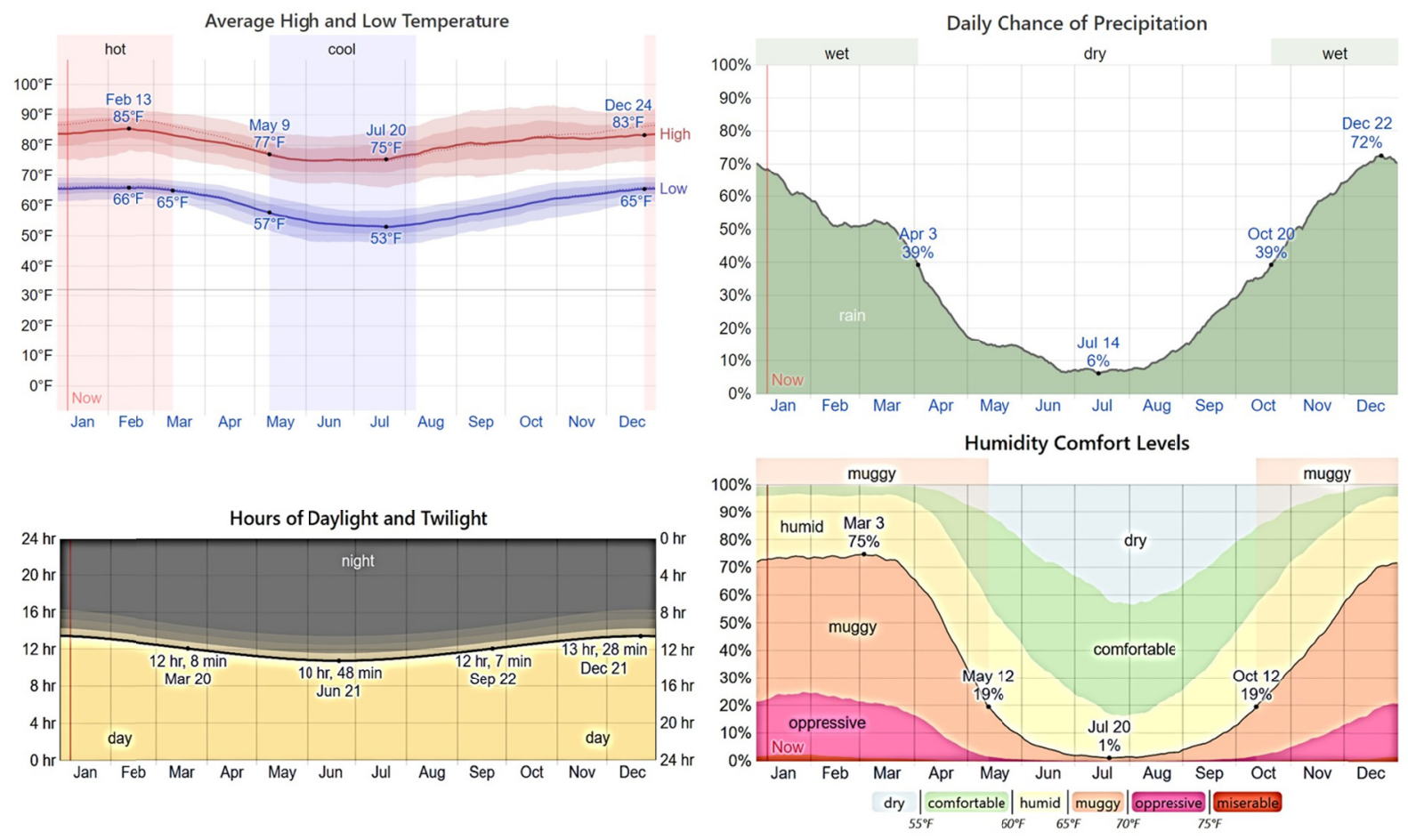

Figure 1. Climatic variation of the study site

Source: Weather Spark, 2021

\section{Results and Discussion}

\subsection{Characterization of the Marble Waste}

Marble waste present a maximum characteristic size of $4.8 \mathrm{~mm}$, and specific mass of 2.91 and $1.74 \mathrm{~kg} / \mathrm{dm}^{3}$ (Table 3 and Figures 2 and 3). Figure 2 shows that the finer particles of the marble waste are more rounded, 
while the larger ones are more cubic and irregular. This condition can increase the internal friction of the particles during the mixing process, increasing the movement and exudation energy of the composites (Barbosa et al., 2013).
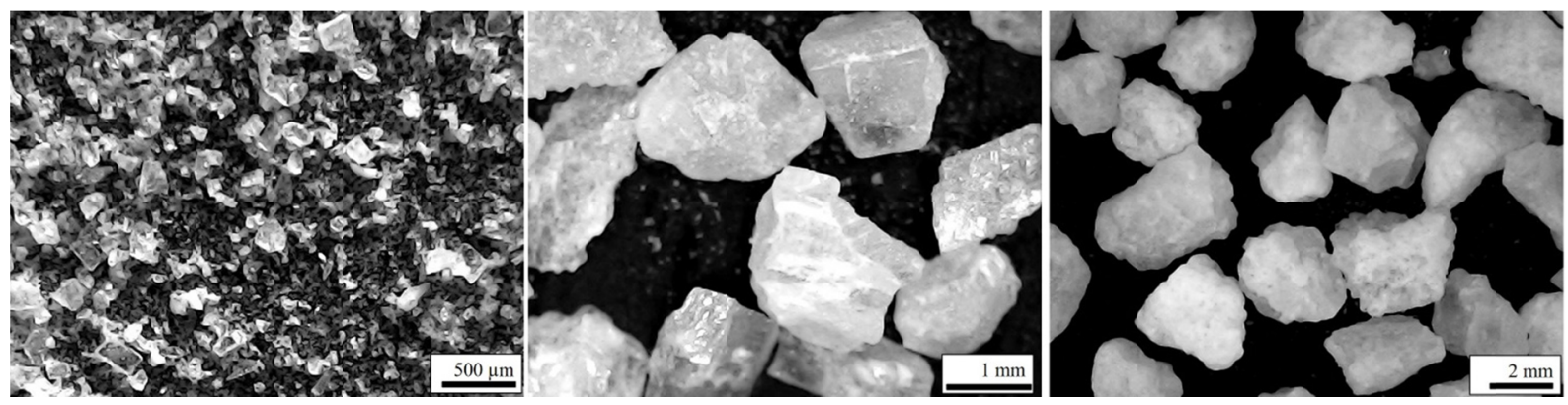

Figure 2. Morphology and particle size distribution of marble waste

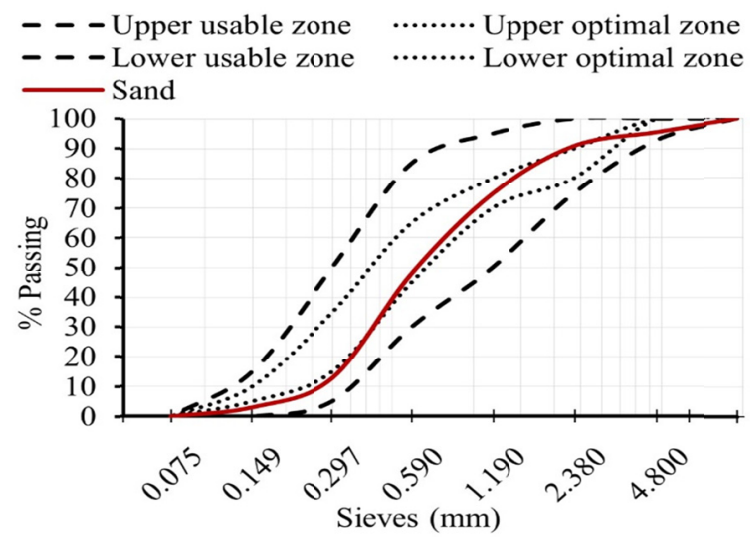

Figure 3. Granulometric distribution of marble waste

Despite the roughness identified (Table 3 and Figures 2 and 3), it is observed that water absorption is low $(1.27 \%)$, being lower than the typical values $(3 \%)$ for natural aggregates. The waste sand grains from marble with rounded shape increase the concrete compactness and improve workability, as well as influence the internal friction angle of the sand grains, improving the dispersion. In addition, the more rounded sand grains reduce the water consumption necessary for the desired consistency of the mixture (Barbosa, Santos \& Coura, 2018). The angular particles produce a more resistant cementitious composite, allowing greater adhesion between them, however, due to the larger specific area, they tend to require more water for the same workability.

Studies carried out (Barbosa et al., 2013) on the reuse of crushed marble waste as an aggregate for the production of mortar and concrete have demonstrated that such wastes do not have enough minerals (such as opal, chalcedony, cristobalite, etc.) that are capable of causing an alkali-aggregate reaction, as shown in Tables 4 and 5 and in Figure 4, which contain the results of the chemical analysis as well as the petrography data of the crushed marble waste. The coarse aggregate, of gneiss origin, has been produced with a maximum diameter of $25.0 \mathrm{~mm}$ and with the following specific mass: 2.70 and $1.36 \mathrm{~kg} / \mathrm{dm}^{3}$.

Table 4. Chemical analysis of crushed marble waste

\begin{tabular}{ll}
\hline Main Elements & Content (\%) \\
\hline $\mathrm{Ca}$ & 18.1 \\
$\mathrm{Mg}$ & 12.9 \\
$\mathrm{Cao}$ & 25.4 \\
$\mathrm{MgO}$ & 7.8 \\
\hline
\end{tabular}

Source: Barbosa, Santos \& Coura, 2018. 
Table 5. Petrographic analysis of crushed marble waste

\begin{tabular}{lll}
\hline Mineral & Chemical Formulation & Percentage \\
\hline Carbonate & $\left(\mathrm{CaCO}_{3}\right)$ or $\left(\mathrm{CaMg}\left(\mathrm{CO}_{3}\right)_{2}\right)$ & $95 \%$ \\
Olivine - Fosterite & $\left(\mathrm{Mg}_{2} \mathrm{SiO}_{4}\right)$ & $3 \%$ \\
Chlorite - Mg & $\left(\mathrm{Mg}_{12}\left[(\mathrm{Si}, \mathrm{Al})_{8} \mathrm{O}_{20}\right](\mathrm{OH})_{16}\right)$ & $*$ \\
Serpentine & $\mathrm{Mg}_{3}\left[\mathrm{Si}_{2} \mathrm{O}_{5}\right](\mathrm{OH})_{4}$ & $*$ \\
Amphibole - Tremolite & {$\left[\mathrm{Ca}_{2} \mathrm{Mg}_{5} \mathrm{Si}_{8} \mathrm{O}_{22}\left(\mathrm{OH}_{2}\right)\right]$} & $*$ \\
\hline
\end{tabular}

Note. $*$ The percentage of the three minerals combined reached $2 \%$ of the sheet. Source: Barbosa, Santos \& Coura, 2018.
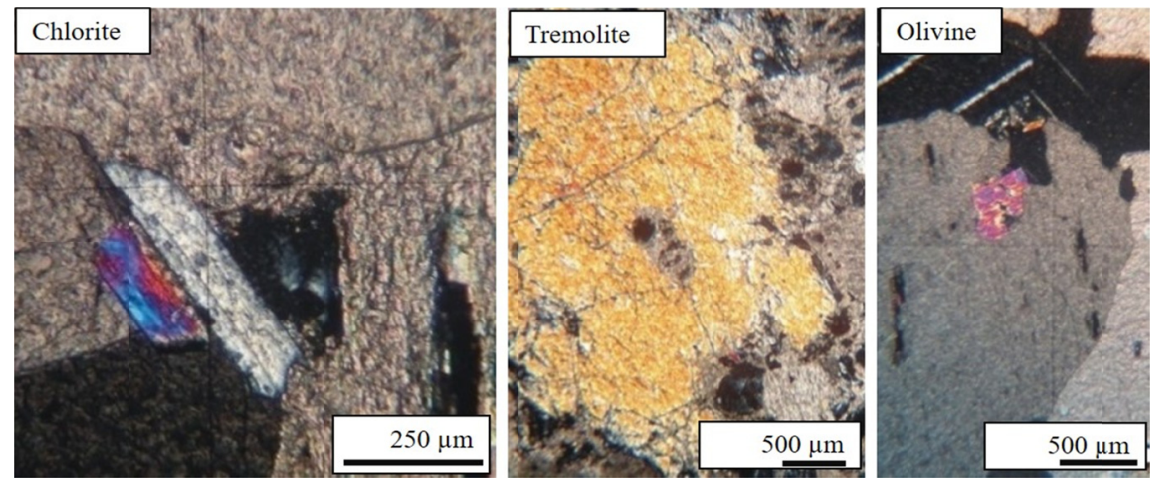

Figure 4. Petrographic analysis images of crushed marble waste

Source: Barbosa, Santos, and Coura, 2018.

\subsection{Characterization of Optical Fibers}

The optical fiber (widely used in telecommunication systems, high-resolution images, assessment of physical and chemical quantities, etc.) is an extremely thin conductor formed by transparent materials that conducts a beam of visible or infrared light, composed of two concentric cylinders: core and cladding (Figure 5). This last one protects the core by controlling and confining the light beam to ensure its propagation across the length of the conductor; in other words, strengthened glass fiber is coated with a polymer that protects it against breaks and impact.

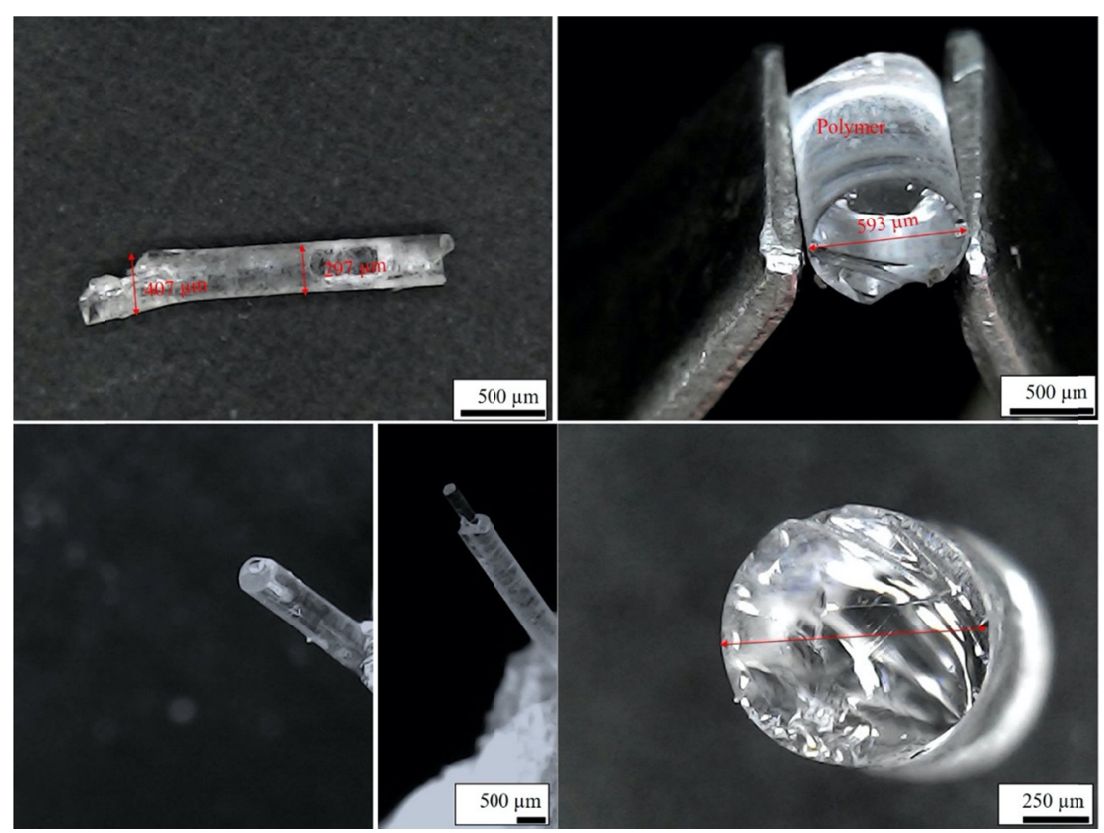

Figure 5. Image of optical fiber waste 
Optical fibers can be considered as hybrid fibers since they are necessarily composed of different crystalline, homogeneous and dielectric materials forming a concentric capillary (Dehghan, Peterson, \& Shvarzman, 2017). The center of these capillaries (inside or core) must have a refraction index greater than that of the layer that wraps it (shell), in order to allow the occurrence of a total internal reflection. Due to this fact, in most cases, the silica/polymer combination (enamel) is used for the core and shell, respectively. The optical fiber waste is composed of silicate, phosphate and germinated glass, with variable diameter filament, from $290 \mu \mathrm{m}$ to $600 \mu \mathrm{m}$, coated with polymer.

\subsection{Raman Spectra Characterization}

In the specific case of Raman spectroscopy (Figure 6), the interpretation of the vibrational spectra can provide some insights regarding the characteristics of the material produced, when compared with the original or conventional cements (Ramírez \& Carrasco, 2011; Liu et al., 2014). As shown in Figure 1, the Raman spectra for each material (as powder) were obtained. Based on the literature produced over the years, it can be assumed that Alite $\left(\mathrm{C}_{3} \mathrm{~S}\right)$ and Belite $\left(\mathrm{C}_{2} \mathrm{~S}\right)$ structures are present in the cement, due to the bands seen in the region between 830 and $880 \mathrm{~cm}^{-1}$; such bands are by far the most analyzed mineral phases of cement, which can be evaluated by Raman spectroscopy; the primary reason is the dominant abundance of calcium silicates in ordinary Portland cement, which is the most common type of cement used worldwide. Bands were observed in the range 400-1100 $\mathrm{cm}^{-1}$, which can be assigned to internal vibrations of the silicate anions, and, more specifically, the bands in the range $780-1000 \mathrm{~cm}^{-1}$ can be attributed to terminal Si-O antisymmetric stretching vibrations $\left(\mathrm{v}_{1}\right.$ and $\left.\mathrm{v}_{3}\right)$. The bands at $400-562 \mathrm{~cm}^{-1}$ can be related to bending modes of the O-Si-O moieties, whereas the bands bellow 400 $\mathrm{cm}-1$ are probably related to $\mathrm{Ca}-\mathrm{O}$ vibrations. Also, the symmetric and antisymmetric bending of the O-Si-O bonds $\mathrm{v}_{2}$ and $\mathrm{v}_{4}$ occur in the range of 300 and $700 \mathrm{~cm}^{-1}$, respectively (Potgieter-Vermaal et al., 2006; Ramírez \& Carrasco, 2011).

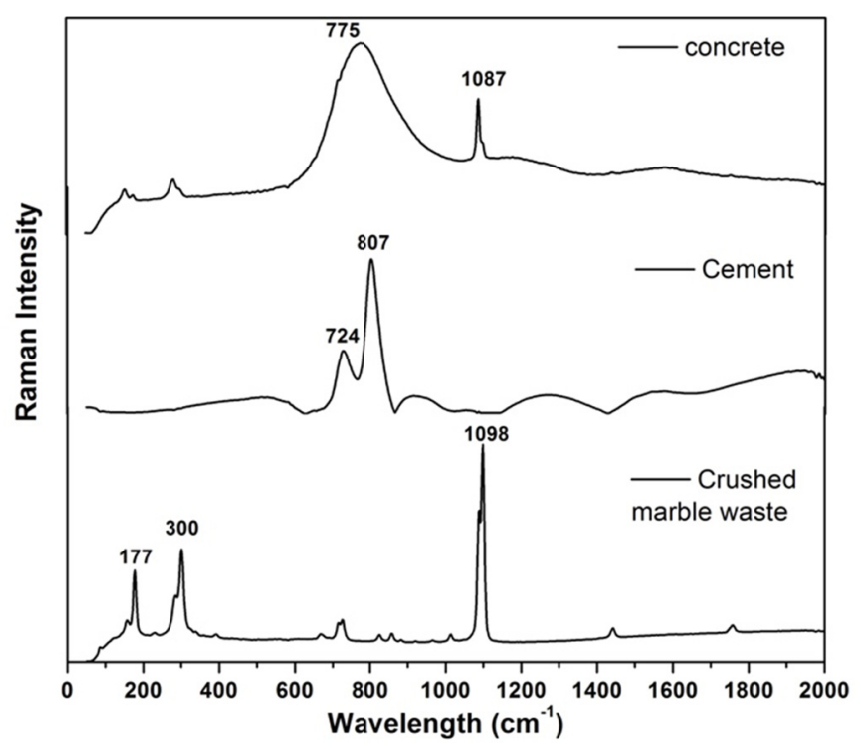

Figure 6. Raman spectra of the materials employed in the production of concrete (cement, crushed marble waste)

By analyzing Figure 6 it is possible to strongly suggest that this aggregate contributes to the formation of a hydrated calcium silicate responsible for the strength gain in Portland cement-based products, which results in an increased durability and life cycle of the composite. There are also stretches with less accentuated curves, which may characterize parts of the material in a semi-crystalline or amorphous state (Vegas et al., 2009; Barbosa \& Santos, 2013; Barbosa et al., 2013).

\subsection{Mechanical Characterization of Concrete}

When optical fibers are added to the concrete, the material (composite) (see Table 6 and Figures 7-11) no longer adopts a fragile behavior, as fibers work as a stress transfer bridge, resulting in a pseudo-ductile material no longer fragile and with certain post-cracking strength capacity, that is, fibers increase the deformation of the 
materials and the load-bearing capacity, notably when submitted to traction, flexo-traction and impact stresses. As seen in Table 6 and in Figures 7 to 11, the composite of this research did not require an increase in water consumption, which favours the rheology of the concrete and, consequently, results in significant gains in the mechanical properties of the composite.

Table 6 . Results (as an average of 6 test specimens) of the tests carried out for concrete mixtures in the ratio 1 : $1.83: 2.83$ (cement : fine aggregate : coarse aggregate).

\begin{tabular}{|c|c|c|c|c|c|c|c|}
\hline Tests & Age (days) & $\begin{array}{c}\text { w/c ratio } \\
0.50 \\
\text { without fiber }\end{array}$ & SE & $\begin{array}{c}\text { w/c ratio } \\
0.46 \\
\text { without fiber }\end{array}$ & SE & $\begin{array}{c}\text { w/c ratio } \\
\quad 0.46 \\
\text { with fiber }\end{array}$ & SE \\
\hline \multirow[t]{3}{*}{ Compressive strength $(\mathrm{MPa})$} & 3 & 17.750 & 0.011 & 21.202 & 0.001 & 26.17 & 0.0006 \\
\hline & 7 & 24.007 & 0.011 & 30.020 & 0.004 & 39.98 & 0.0005 \\
\hline & 28 & 32.047 & 0.004 & 37.262 & 0.001 & 46.30 & 0.0004 \\
\hline \multirow[t]{3}{*}{ Tensile strength (MPa) } & 3 & 2.342 & 0.002 & 2.900 & 0.000 & 3.53 & 0.0004 \\
\hline & 7 & 3.443 & 0.002 & 4.080 & 0.000 & 5.16 & 0.0004 \\
\hline & 28 & 4.230 & 0.001 & 4.330 & 0.000 & 5.39 & 0.0004 \\
\hline Flexural strength (MPa) & 28 & 4.760 & 0.001 & 4.890 & 0.000 & 6.15 & 0.0001 \\
\hline Elasticity modulus (GPa) & 28 & 49.915 & 0.006 & 51.030 & 0.001 & 40.93 & 0.0003 \\
\hline
\end{tabular}

It can be seen in Figure 7 that the compressive strength increased (about 20\%) with the reduction of the water/cement ratio, as expected (Barbosa et al., 2013; Almada et al., 2020). The use of fibers from optical fiber waste also increased the values by 23 to $33 \%$. The presence of the fiber helped the final strength to be reached more quickly due to the filler effect, generating nucleation, and thus accelerating the hydration reactions of the cement (Grabois, Cordeiro \& Filho, 2016). The break presented a first stage of rupture when it was activated to the fibers and in the sequence, with the maintenance of the load until the final rupture in the shape of a bar subjected to axial compression efforts.
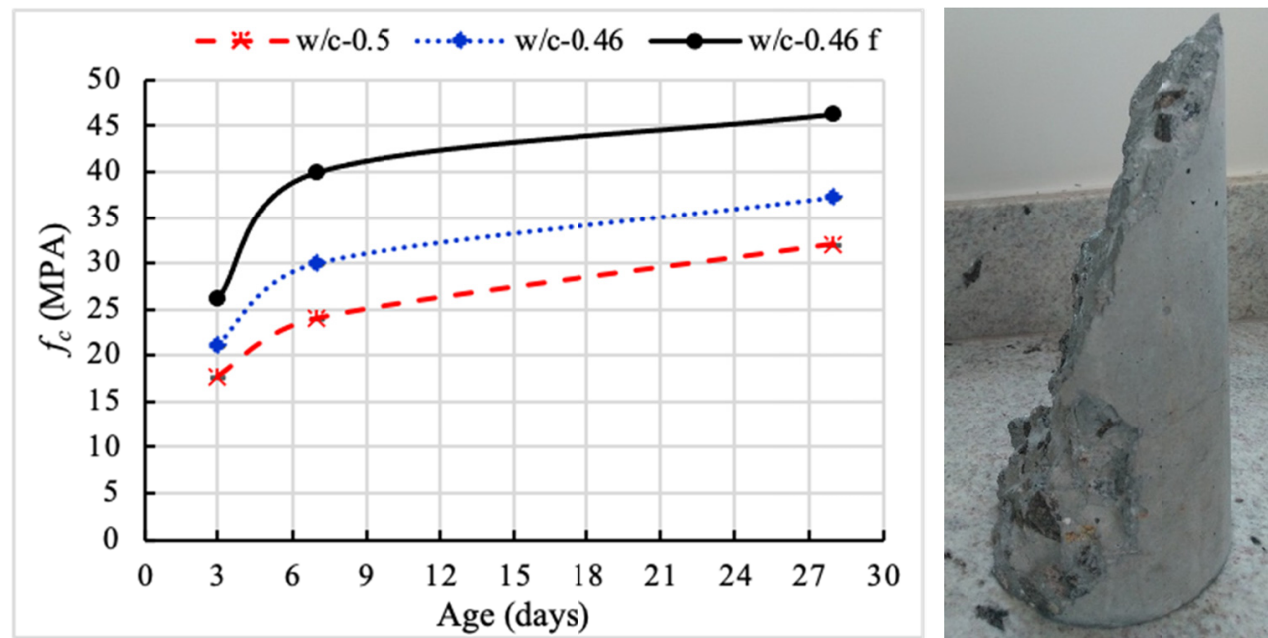

Figure 7. Compressive strength $\left(f_{c}\right)$ of concrete

A similar phenomenon can be seen in the tensile strength (Figure 8), which presents an increase with the reduction of the water/cement ratio by $20 \%$, while the fiber generated increases between 22 and $26 \%$. Therefore, it can be inferred that the presence of the optical fiber tends to increase the mechanical properties, due to both the filler effect and the mechanical anchoring effect in cracking situations, either by drying retraction or even by loading as performed in the tensile strength by division (Yap et al., 2015).

Another point to highlight is the ratio between $f_{t} / f_{c}$ (Figure 9), which was constant (about 13\%), demonstrating that the filler effect arising from the presence of the fiber was more prevalent than the mechanical effect (tensile/adhesion). When the mechanical effect appears, there is an increase in the ratio due to the tensile effect, preventing the micro-cracks from spreading and causing rupture (Yap et al., 2015b). 


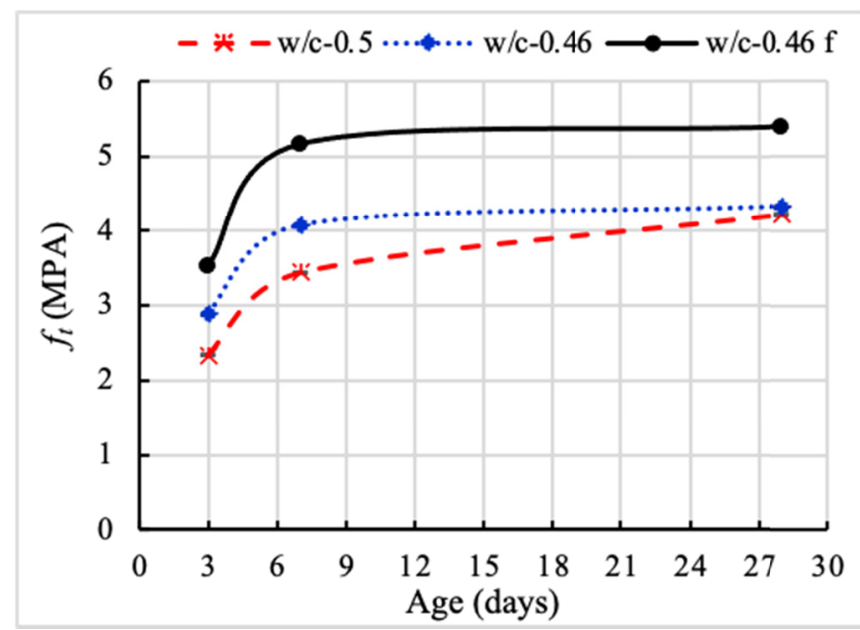

Figure 8 . Tensile strength $\left(f_{t}\right)$ of concrete

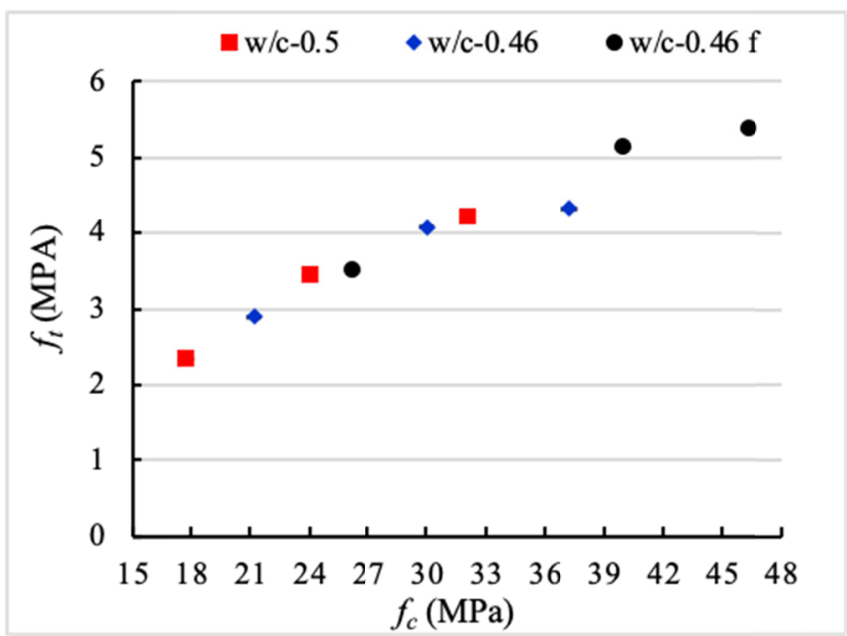

Figure 9. Tensile strength $\left(f_{t}\right)$ versus compressive strength $\left(f_{c}\right)$ of concrete

When analyzing Figure 10, it is possible to identify several fibers broken by tensile strength together with the concrete and the aggregate (internal rupture and in the aggregate/paste interface), demonstrating that the rupture stress of the fiber is adequate in relation to the strength of the composite, emphasizing its viability. When looking at the interface (Figure 10), it can be seen that the fiber has shifted in relation to the concrete when subjected to the tensile strength, which may demonstrate a lower adhesion capacity between the fiber and the matrix. The presence of the polymer may have generated this lower strenght. It is noteworthy, however, that the concrete with marble sand and optical fiber waste presented sufficiently high and satisfactory values for the wastes to meet the requirements of their use in structural concretes.

Regarding the tensile strength in flexion (Figures 8, 9 and 10), the value remained unchanged with the w/c variation, but there was an increase of $26 \%$ regarding the presence of optical fibers. It is noticed that the fiber tends to influence this property more and to significantly improve the behavior of the concrete. This was expected for conventional fibers (steel, polymers, natural) (Yap at al., 2015; Bosnjak, Ozbolt \& Hahn, 2013) and, with the use of a waste from optics fiber, excellent results are found, demonstrating the potential use of these waste.

As for the modulus of elasticity (Figure 11), there is a behavior similar to that of traction in flexion, in which the reduction in the amount of water generated an insignificant increase (2\%). However, in relation to the presence of fibers, a reduction of $20 \%$ was observed. The lower fiber/matrix adhesion, consequence of the presence of the polymeric coating, increased the deformation capacity of the matrix, while the presence of fibers increased the ductility, allowing the reinforced composite resulting from the addition of fibers to deform further before 
breaking. This property is important for concrete subjected to cyclic loading; therefore, the use of these fibers would maximize the ways of using this concrete and the reuse of waste.

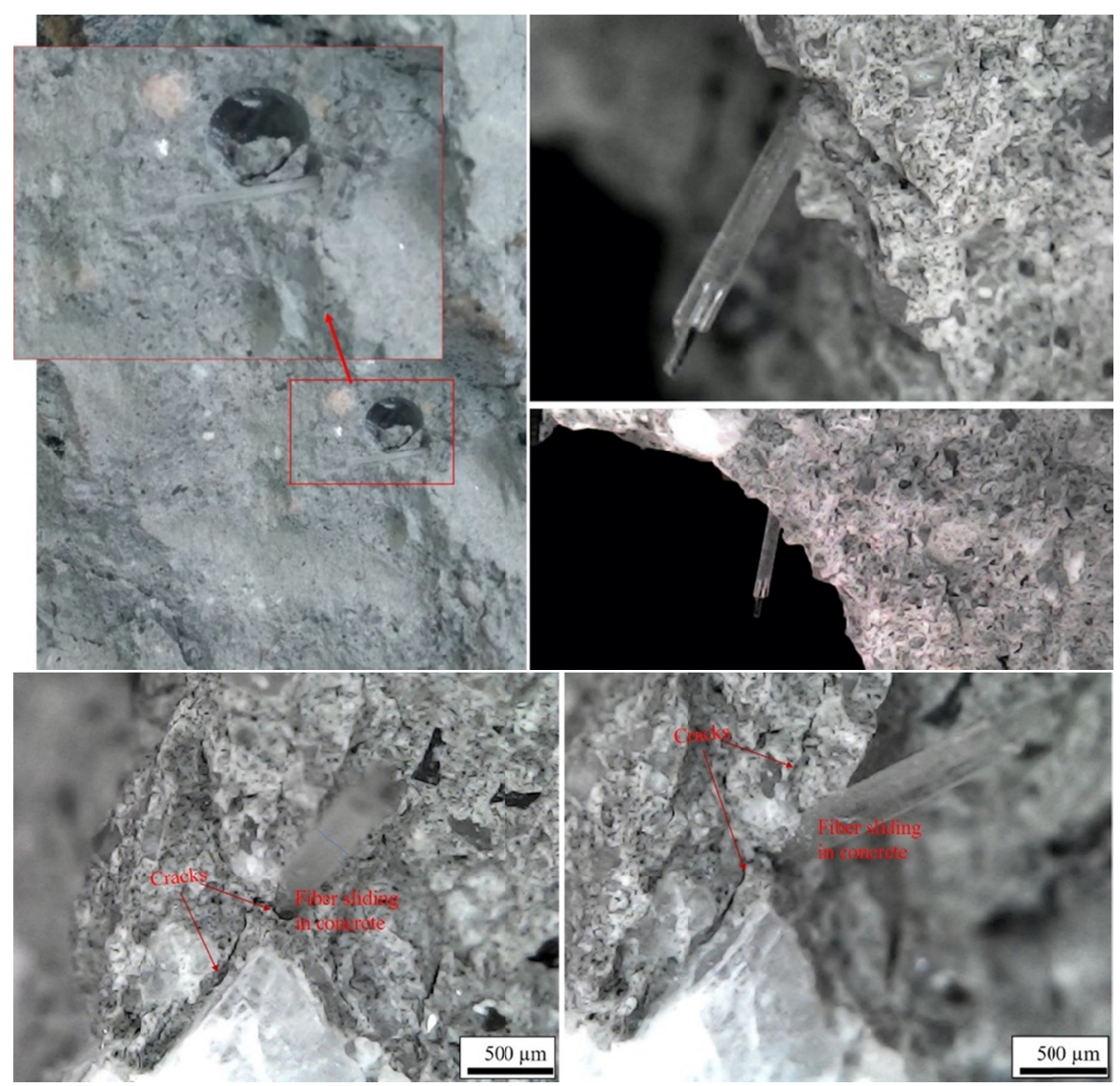

Figure 10. Fiber sliding in concrete

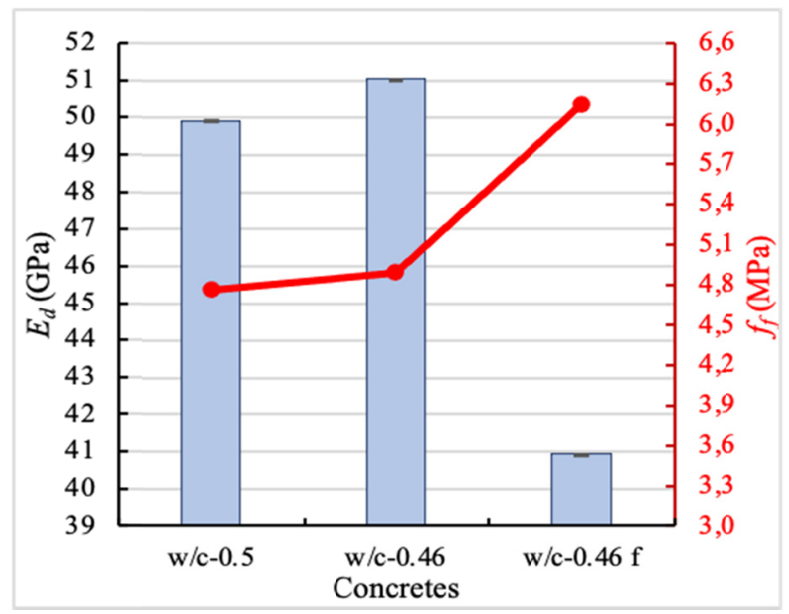

Figure 11. Flexural strength $\left(f_{f}\right)$ and Elasticity modulus $\left(E_{d}\right)$ of concrete with crushed marble waste

\subsection{Analysis of the Microstructure of Optical Fiber Waste in Concretes After 5 Years}

It appears (Figures 12 to 14 ) that, as to the durability and life cycle of the optical fiber waste in the alkaline composite matrix (Portland cement), considering a 5-year integrity, there was no degradation of the fiber caused by the alkalinity of the cement, consequently ensuring the longevity of the composite. It was found that the 
application of a polymeric treatment on the surface of the optical fiber tends to preserve its main function (transmission) and to reduce a drop in impact strength, which also prevents its destruction by calcium hydroxide $\left(\mathrm{Ca}(\mathrm{OH})_{2}\right)$ generated in the hydration of the cement.

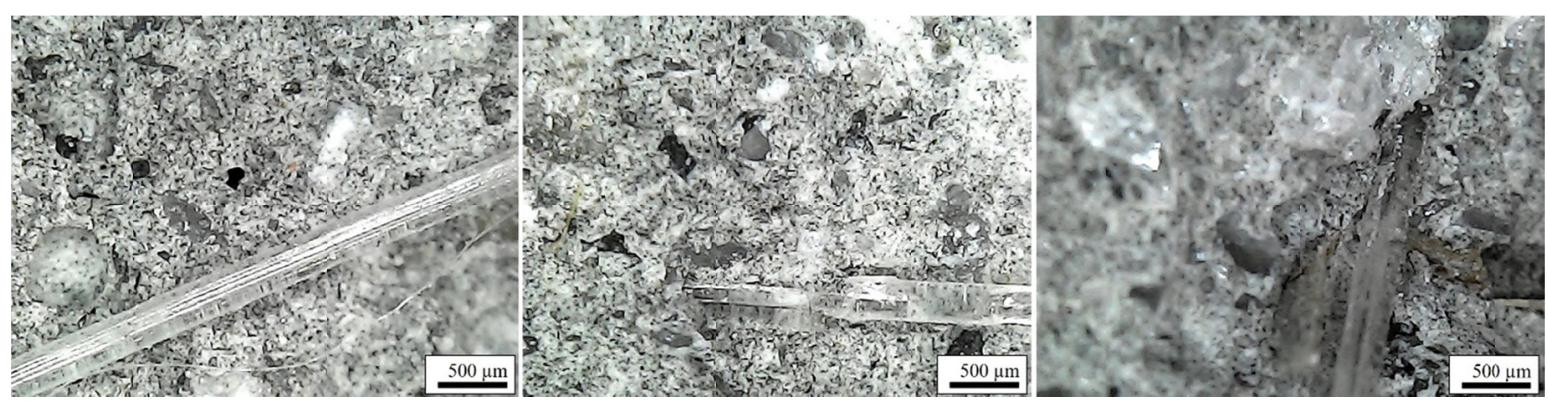

Figure 12. Images of reinforced concrete with optical fiber after 5 years



Figure 13. SEM of the optical fiber interface with concrete after 5 years

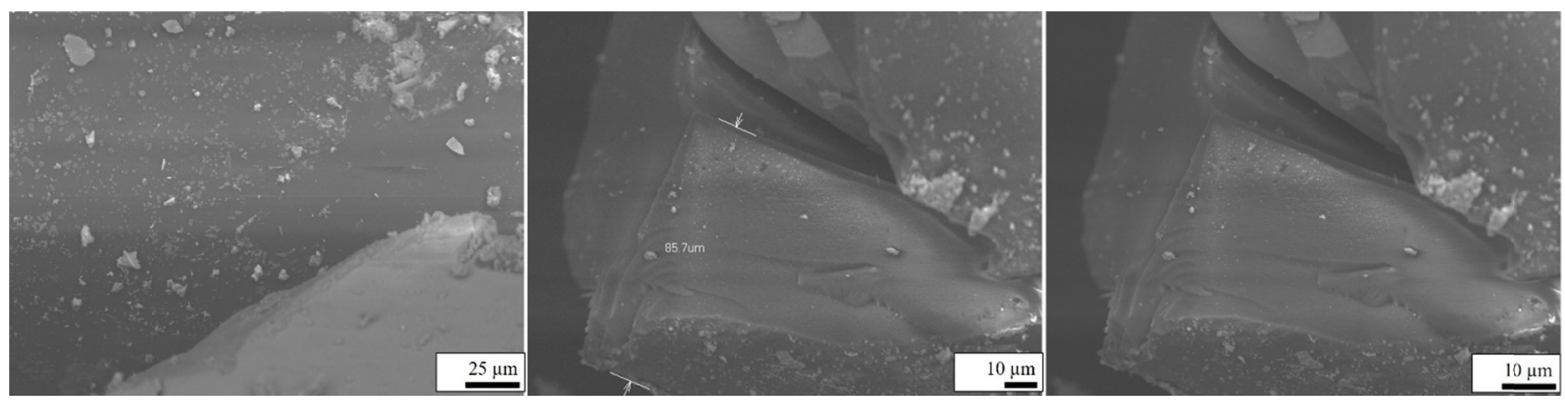

Figure 14. SEM of reinforced concrete with optical fiber after 5 years

Figures 13 and 14 show that the matrix interface and the fiber remain unchanged and there will be complete compatibility between the two materials. Therefore, although the polymer reduces adhesion, and with this the modulus of elasticity, it was found that it avoids reactions with the alkaline matrix, making it the most efficient material over its life cycle. When analyzing Figure 13, which presents images of the fibers after breaking, it is possible to observe the impregnation of the hydrated compounds in the polymeric coating, however, again no wear was seen on the fibers. Therefore, these fibers, together with the marble waste, are suitable for use in structural concretes.

Among the several types of fibers employed in the concrete reinforcement (steel, nylon, carbon, vegetables, etc.), the employment of conventional glass fiber is hindered by the degradation that occurs over time in its physical properties, reducing the durability of the composite. This is mainly because the alkalinity of the Portland cement matrix affects the tenacity and progressively reduces flexibility, making the composite fragile. In order to prevent degradation of the glass fibers, and to increase the durability of the composite, the following alternatives are 
recommended (Dhir et al., 2004; Reis et al., 2009; Fathi et al., 2017; Dehghan, Peterson, \& Shvarman, 2017):

i) The increase in fiber resistance is achieved by using alkali-resistant (AR) fibers, that is, fibers composed of about $16 \%$ of zirconium oxide $\left(\mathrm{ZrO}_{2}\right)$; however, their cost is relatively high (approximately 3 times the cost of the conventional version), thus making it economically unviable;

ii) Surface protection of fibers (allowing "encapsulation" of the fiber), preventing contact with hydrated surfaces, that is, making them more resistant to the alkaline attack of cement;

iii) Change of the cement matrix through the use of low alkalinity cements and/or the addition of minerals capable of reducing the $\mathrm{pH}$ of porous solutions, or by eliminating the formation of calcium hydroxide, or by modifying the mixture of concrete and latex (reducing the formation of $\left.\mathrm{Ca}(\mathrm{OH})_{2}\right)$.

\section{Conclusions}

The recycling process of waste should follow an appropriate methodology so that the products developed may present performances compatible with the technical standards and do not cause environmental risks. With regard to waste, the object of this research, it is clear that the results are compatible with, and even higher to, the technical standards, reinforcing the great benefits. The main conclusions drawn regarding the use of marble waste as an aggregate and optical fiber waste for the production of mixed concrete was that the concrete with marble waste has good mechanical properties and the addition of optical fiber waste improved the performance of the concrete.

As an indicator of long-term sustainability, it can be used in concrete to achieve one or several of the following: replacement of non-renewable materials with recycled materials or waste; reduction in energy requirements in the manufacture of concrete; improvement in the durability of concrete in a particular environment; reduction in the cost of materials; utilization of local unconventional raw materials (for example: marble waste and/or optical fiber waste) in low-cost concrete.

It can be concluded that the inclusion of waste:

i) Results in an increase of about $20 \%$ in mechanical properties. Such fact can be justified by the higher density and by the tensile effect, preventing the micro-cracks from spreading and propagating in the rupture of the studied specimen;

ii) Regarding flexural strength and modulus of elasticity, these properties are extremely important in very specific areas: impact forces, support conditions, among others, being that, for the reinforced composite, the results of the addition of fibers tend to result in a reduction in the rigidity of the mixture, making the composite material more ductile;

iii) Surface protection of the fibers prevented contact with hydrated surfaces, making them more resistant to the alkaline attack of the cement.

Specifically, for the building industry, the accumulation of construction and demolition waste in inappropriate or scarce areas, not to mention the growing demand for materials, is considered a current social and economic problem. The "green" materials, which have high durability, high properties, low maintenance requirements and contain a large proportion of recycled or recyclable materials, are important for the planet and this composite includes the concept of sustainability (environmental, social and economic).

\section{Acknowledgments}

The authors wish to thank the National Council for Scientific and Technological Development (CNPq), Coordination of Superior Level Staff Improvement (CAPES), Foundation for Research Support of the State of Minas Gerais (FAPEMIG), Federal University of Juiz de Fora (UFJF) and Federal University of Minas Gerais (UFMG) for their financial support.

\section{References}

Aliabdo, A., Elmoaty, A., \& Auda, E. M. (2014). Re-Use of Waste Marble Dust in the Production of Cement and $\begin{array}{llll}\text { Concrete. Construction and } & \text { Building }\end{array}$ https://doi.org/10.1016/j.conbuildmat.2013.09.005

Almada, L. S., Melo, D. J. B., Bubani, L. C., Silva, G. J., Santos, W. J., \& Aguilar, M. T. (2020). Influence of the heterogeneity of waste from wet processing of ornamental stones on the performance of Portland cement $\begin{array}{lllll}\text { composites. Construction and Building } & 120036 .\end{array}$ https://doi.org/10.1016/j.conbuildmat.2020.120036

Alvarenga, C. B. C. S., Heiderick, O. M., Couto, T. A., Cetlin, P. R., Sales, R. B. C., \& Aguilar, M. T. P. (2019). Influence of soda-lime waste glass microparticles on workability and thermal properties of portland cement 
compounds. Materiales de Construcción, 69(335). https://doi.org/10.3989/mc.2019.05818

Alyamaç, K., \& Ince, R. (2009). A preliminary concrete mix design for SCC with marble powders. Construction and Building Materials, 23(3), 1201-1210. https://doi.org/10.1016/j.conbuildmat.2008.08.012

Arel, H. (2016). Recyclability of waste marble in concrete production. Journal of Cleaner Production, 131, 179-188. https://doi.org/10.1016/j.jclepro.2016.05.052

Ashish, D. (2018). Feasibility of waste marble powder in concrete as partial substitution of cement and sand amalgam for sustainable growth. Journal of Building Engineering, 15, 236-242. https://doi.org/10.1016/j.jobe.2017.11.024

Ashish, D. (2019). Concrete made with waste marble powder and supplementary cementitious material for sustainable development. Journal of Cleaner Production, 211, 716-729. https://doi.org/10.1016/j.jclepro.2018.11.245

Barbosa, M. T., Maia, M., Castanõn, J., \& Ludwig, Z. (2013). ECODOR: sustainable proportion for concrete sleeper. Procedings of Portugal SB13 - Contribuition of sustainable building to meet EU 20-20-20 Targets. Proceedings 1 (pp. 365-370).

Barbosa, M. T., \& Santos, W. (2013). ARGAD: High Performance Mortar (vol. 1, pp. 387-394). In Portugal SB13 - Contribuition of sustainable building to meet EU 20-20-20 Targets.

Barbosa, M. T., Santos, W. J., \& Coura, C. V. (2018). High quality of mortar with marble waste aggregate. Ambiente Construído, 18(2). https://doi.org/10.1590/s1678-86212018000200260

Bosnjak, J., Ožbolt, J., \& Hahn, R. (2013). Permeability measurement on high strength concrete without and with polypropylene fibers at elevated temperatures using a new test setup. Cement and Concrete Research, 53, 104-111. https://doi.org/10.1016/j.cemconres.2013.06.005

Brazilian Association of Technical Norms (ABNT). (1991). NBR 5733. High strength Portland cement. Rio de Janeiro.

Buyuksagis, I. S., Uygunoglu, T., \& Tatar, E. (2017). Investigation on the usage of waste marble powder in cement-based adhesive mortar. Construction and Building Materials, 154, 734-742. https://doi.org/10.1016/j.conbuildmat.2017.08.014

Chen, G., Lee, H., Young, K., Yue, P., Wong, A., Tao, T., \& Choi, K. (2002). Glass recycling in cement production-an innovative approach. Waste Manage., 22, 747-753. https://doi.org/10.1016/S0956-053X(02)00047-8

Cox, R. A., Drews, M., Rode, C., \& Nielsen, S. B. (2014). Simple Future Weather Files for Estimating Heating and Cooling Demand. Building and Environment, 83, 104-114. https://doi.org/10.1016/j.buildenv.2014.04.006

Dehghan, A., Peterson, K., \& Shvarzman, A. (2017). Recycled glass fiber reinforced polymer additions to Portland cement concrete. Construction and Building Materials, 146, 238-250. https://doi.org/10.1016/j.conbuildmat.2017.04.011

Dhir, R., Dyer, T., Tano, A., \& Cui, Y. (2004). Towards maximizing the value and sustainable use of glass. Concrete, 38, 38-40.

Fathi, H., Lameie, T., Maeki, M., \& Yazdani, R. (2016). Simultaneous effects of fiber and glass on the mechanical properties of self-compacting concrete. Construction and Building Materials, 133, 443-449. https://doi.org/10.1016/j.conbuildmat.2016.12.097

Ge, Z., Wangb, H., Zhang, Q., \& Xiong, C. (2015). Glass fiber reinforced asphalt membrane for interlayer bonding between asphalt overlay and concrete pavement. Construction and Building Materials, 101, 918-925. https://doi.org/10.1016/j.conbuildmat.2015.10.145

Grabois, T., Cordeiro, G., \& Filho, R. (2016). Fresh and hardened-state properties of self-compacting lightweight concrete reinforced with steel fibers. Construction and Building Materials, 104, 284-292. https://doi.org/10.1016/j.conbuildmat.2015.12.060

Kou, S., Poon, C., \& Agrela, F. (2011). Comparisons of natural and recycled aggregate concretes prepared with the addition of different mineral admixtures. Cement and Concrete Composites, 33(8), 788-795. https://doi.org/10.1016/j.cemconcomp.2011.05.009

Lanzoni, L., Nobili, A., \& Tarantino, A. (2012). Performance evaluation of a polypropylene-based draw-wired 
fibre for concrete structures. Construction and Building Materials, 28(1), $798-806$. https://doi.org/10.1016/j.conbuildmat.2011.10.017

Lee, G., Ling, T., Wong, Y., \& Poon, C. (2011). Effects of crushed glass cullet sizes, casting methods and pozzolanic materials on ASR of concrete blocks. Construction and Building Materials, 25(5), 2611-2618. https://doi.org/10.1016/j.conbuildmat.2010.12.008

Ling, T., Poon, C., \& Kou, S. (2012). Influence of recycled glass content and curing conditions on the properties of self-compacting concrete after exposure to elevated temperatures. Cement and Concrete Composites, 34(2), 265-272. https://doi.org/10.1016/j.cemconcomp.2011.08.010

Liu, F., Masce, S., Sun, Z., \& Qi, C. (2014). Raman spectroscopy study on the hydration behaviors of Portland cement pastes during setting. Journal of Materials in Civil Engineering, 27(8). https://doi.org/10.1061/(ASCE)MT.1943-5533.0001189

Medina, C., Rojas, M., \& Frías, M. (2013). Properties of recycled ceramic aggregate concretes: Water resistance. Cement and Concrete Composites, 40, 21-29. https://doi.org/10.1016/j.cemconcomp.2013.04.005

Munir, M., Kazmi, M., \& Wu, S. (2017). Efficiency of waste marble powder in controlling alkali-silica reaction of concrete: A sustainable approach. Construction and Building Materials, 154, 590-599. https://doi.org/10.1016/j.conbuildmat.2017.08.002

Pereira-Mercado, Y., Santiago-Rodriguez, I., Saucedo-Salazar, E., Rodiguez-Ruiz, F., Garcia-Rodriguez, S., Le_on, G., ... Arauza-Villarreal A. (2013). Production of mortars using novel glass-ceramic porous spherical particles with chemical composition into $\mathrm{SiO} 2-\mathrm{CaO}-\mathrm{A} 12 \mathrm{O} 3-\mathrm{MgO}$ quaternary system as replacement of sand aggregates. Cement and Concrete Composites, 73, $105-113$. https://doi.org/10.1016/j.cemconcomp.2016.07.009

Potgieter-vermaak, S., Potgieter, J., Belleil, M., De Weerdt, F., \& Van Grieken, R. (2006). The application of Raman spectrometry to the investigation of cement. Part II: A micro-Raman study of OPC, slag and fly ash. Cement and Concrete Research, 36(4), 656-662. https://doi.org/10.1016/j.cemconres.2005.09.008

Ramírez, S., \& Carrasco, L. (2011). Raman spectroscopy: Application to cementitious systems. Construction and Building: Design, Materials, and Techniques, 233-244.

Reis, J., Nunes, L., Triques, A., Valente, L., \& Braga, A. (2009). Mechanical characterization using optical fiber sensors of polyester polymer concrete made with recycled aggregates. Materials Research, 12(3). https://doi.org/10.1590/S1516-14392009000300004

Sales, R., Sales, F., Figueiredo, E., Santos, W. J., Mohallem, N., \& Aguilar, M. T. (2017). Durability of Mortar Made with Fine Glass Powdered Particles. Advances in Materials Science and Engineering. https://doi.org/10.1155/2017/3143642

Sardinha, M., Brito, J., \& Rodrigues, R. (2016). Durability properties of structural concrete containing very fine aggregates of marble sludge. Construction and Building Materials, 119, 45-52. https://doi.org/10.1016/j.conbuildmat.2016.05.071

Shayan, A., \& Xu, A (2006). Performance of powder as pozzolanic materials in concrete: A filed trail on concrete slabs. Cement and Concrete Research, 36(3), 457-468. https://doi.org/10.1016/j.cemconres.2005.12.012

Singh, M., Srivastava, A., \& Bhunia, D. (2018). Long term strength and durability parameters of hardened concrete on partially replacing cement by dried waste marble powder slurry. Congress on Technical Advancement 2017. https://doi.org/10.1061/9780784481035.007

Vardhan, K., Goyal, S., Siddique, R., \& Singh, M. (2015). Mechanical properties and microstructural analysis of cement mortar incorporating marble powder as partial replacement of cement. Construction and Building Materials, 96, 615-621. https://doi.org/10.1016/j.conbuildmat.2015.08.071

Vegas, I., Azkarate, I., Juzrrero, A., \& Frias, M. (2009). Design and performance of mansory mortars made with recycled concrete aggregates. Materials de Constuccion.

Viana, T., Bacelar, B., Coelho, I., Ludvig, P., \& Santos, W. J. (2020). Behaviour of ultra-high-performance concretes incorporating carbon nanotubes under thermal load. Construction and Building Materials, 263, 120556. https://doi.org/10.1016/j.conbuildmat.2020.120556

Weather Spark. (2021). Retrieved January $\quad 8, \quad$ 2021, from https://weatherspark.com/y/30589/Average-Weather-in-Juiz-de-Fora-Brazil-Year-Round 
Yap, S., Alengaram, U., Jumaat, M., \& Khaw, K. (2015b). Torsional behaviour of steel fibre-reinforced oil palm shell concrete beams. Materials \& Design, 87, 854-862. https://doi.org/10.1016/j.matdes.2015.08.078

Yap, S., Khaw, K., Alengaram, U., \& Jumaat, M. (2015a). Effect of fibre aspect ratio on the torsional behaviour of steel fibre-reinforced normal weight concrete and lightweight concrete. Engineering Structures, 101, 24-33. https://doi.org/10.1016/j.engstruct.2015.07.007

\section{Copyrights}

Copyright for this article is retained by the author, with first publication rights granted to the journal.

This is an open-access article distributed under the terms and conditions of the Creative Commons Attribution license (http://creativecommons.org/licenses/by/4.0/). 